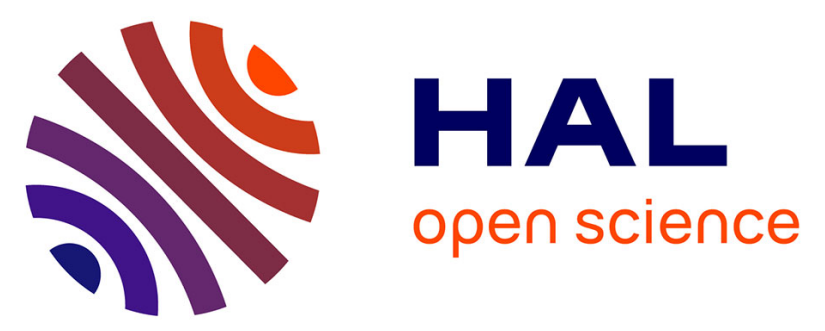

\title{
Analysis of multiclass organic pollutant in municipal landfill leachate by dispersive liquid-liquid microextraction and comprehensive two-dimensional gas chromatography coupled with mass spectrometry Mihail Simion Beldean-Galea, Jérôme Vial, Didier Thiebaut, Maria-Virginia Coman
}

\section{To cite this version:}

Mihail Simion Beldean-Galea, Jérôme Vial, Didier Thiebaut, Maria-Virginia Coman. Analysis of multiclass organic pollutant in municipal landfill leachate by dispersive liquid-liquid microextraction and comprehensive two-dimensional gas chromatography coupled with mass spectrometry. Environmental Science and Pollution Research, 2020, 27 (9), pp.9535-9546. 10.1007/s11356-019-07064-z . hal-03065174

\author{
HAL Id: hal-03065174 \\ https://hal.science/hal-03065174
}

Submitted on 14 Dec 2020

HAL is a multi-disciplinary open access archive for the deposit and dissemination of scientific research documents, whether they are published or not. The documents may come from teaching and research institutions in France or abroad, or from public or private research centers.
L'archive ouverte pluridisciplinaire HAL, est destinée au dépôt et à la diffusion de documents scientifiques de niveau recherche, publiés ou non, émanant des établissements d'enseignement et de recherche français ou étrangers, des laboratoires publics ou privés. 


\title{
Analysis of multiclass organic pollutant in municipal landfill leachate by dispersive liquid-liquid microextraction and comprehensive two-dimensional gas chromatography coupled with mass spectrometry
}

\author{
Mihail Simion Beldean-Galea ${ }^{1 *}$, Jerôme Vial ${ }^{2}$, Didier Thiébaut ${ }^{2}$, Maria-Virginia Coman ${ }^{3}$ \\ ${ }^{I}$ Babeș-Bolyai University, Faculty of Environmental Science and Engineering, 30 Fântânele Street, RO- \\ 400294,Cluj-Napoca, Romania \\ ${ }^{2}$ École Supérieure de Physique et de Chimie Industrielles de la Ville de Paris, UMR CNRS CBI, PSL \\ Research Institute, 10 rue Vauquelin, 75231 Paris Cedex 05, France \\ ${ }^{3}$ Babeș-Bolyai University, "Raluca Ripan” Institute for Research in Chemistry, 30 Fântânele Street, \\ RO-400294 Cluj-Napoca, Romania
}

*corresponding author simion.beldean@yahoo.com

\begin{abstract}
We propose a simple, fast and inexpensive method for the analyses of 72 organic compounds in municipal landfill leachate, based on dispersive liquid-liquid microextraction and comprehensive two-dimensional gas chromatography coupled with mass spectrometry. 41 organic compounds belonging to several classes including hydrocarbons, mono- and polyaromatic hydrocarbons, carbonyl compounds, terpenes, terpenoids, phenols, amines, and phthalates, covering a wide range of physicochemical properties and linked to municipal landfill leachate, were quantitatively determined. Another 31 organic compounds such as indoles, pyrroles, glycols, organophosphate flame retardants, aromatic amines and amides, pharmaceuticals, bisphenol A etc. have been identified based on their mass spectra. The developed method provides good performances in terms of extraction recovery $(63.8-127 \%)$, intra-day and inter-day precisions ( $<7.7$ and $<13.9$ respectively), linearity ( $\mathrm{R}^{2}$ between 0,9669 - 0.9999), detection limit $\left(1.01-69.30 \mu \mathrm{g} \mathrm{L}^{-1}\right)$, quantification limit $\left(1.87-138.6 \mu \mathrm{g} \mathrm{L}^{-1}\right)$ and
\end{abstract}


enrichment factor $(69.6$ - 138.5). Detailed information on the organic pollutants contained in municipal landfill leachate could be obtained with this method during a 40 minute analysis of a $4 \mathrm{~mL}$ leachate sample, using only $75 \mu \mathrm{L}$ of extraction solvent.

Keywords: municipal landfill leachate, organic pollutants, dispersive liquid-liquid microextraction; GC×GC-qMS

\section{Introduction}

Solid waste management is a challenge faced by both industrialized and developing countries. Even if the selective collection of solid waste fractions - including plastics, paper, glass, metals, and electronic waste - has been already implemented in many countries, there is still a vast quantity of waste that is disposed of as municipal landfill (Mavakala et al. 2016).

The disposal of municipal waste into landfills is therefore one of the primary options adopted by many countries worldwide due to its economic advantages (Ranou et al. 2008). Between the numerous challenges that appear due to the unplanned development of landfill areas, inadequate engineering controls or oversaturation (Mukherjee et al. 2015), the problems caused by the pollution by gaseous emissions of volatile organic compounds, airborne particulate matter and leachate is one of the main concerns of the urbanized areas (Tigini et al. 2014).

Leachate is a black/brown liquid formed as a consequence of waste degradation and of rainwater percolation through waste layers at landfill sites (Baderna et al. 2011). The washing action of rainwater draws different classes of chemical compounds from waste such as heavy metals, inorganic ions $\left(\mathrm{NH}_{4}{ }^{+}, \mathrm{NH}_{3}, \mathrm{NO}_{3}{ }^{-}, \mathrm{SO}_{4}{ }^{2-}, \mathrm{PO}_{4}{ }^{3-}, \mathrm{Cl}^{-}\right.$etc. $)$and persistent organic pollutants, most of them being highly toxic to the environment and to human health (Pivato and Gaspari 2005; Ghosh et al. 2017; Khalil et al. 2018). 
Generally, the basal composition of most leachates is characterized by four groups of pollutants: (a) dissolved organic matter expressed as Chemical Oxygen Demand (COD) or Total Organic Carbon (TOC); (b) inorganic salts and ammonia; (c) heavy metals and (d) xenobiotic organic compounds of different classes (Öman and Junestedt 2008; Huang et al. 2009; Pastore et al. 2018). This composition may be affected by many factors such as landfill age, geological and hydrogeological conditions, local weather, internal temperature, $\mathrm{pH}$ and interaction of various chemicals (Khalil et al. 2018) and, therefore, an exhaustive characterization of all chemicals presented in municipal landfill leachate becomes a challenge.

Moreover, the identification of contaminants, especially in the case of xenobiotic organic compounds, is difficult because of: the variety of chemicals present; the limited number of chemicals being routinely analyzed; the complexity and diversity of leachate from different sources (Budi et al. 2016) and also, the limited number of chemical standards available. Hence, the traditional way of identifying chemicals becomes really complicated.

Studies performed so far have revealed over 200 organic compounds of hazardous nature in landfill leachate (Khalil et al. 2018). The most frequently identified compounds include: halogenated aliphatic compounds, benzene and alkylated benzenes, phenol and alkylated phenols, chlorinated benzenes, chlorinated phenols (Kumarathilaka et al. 2016; Qi et al. 2018), ethoxylates, polycyclic aromatic compounds, phthalate esters (Jernberg et al. 2013; Qi et al. 2018), mercaptans (Borrás et al. 2016), pesticides, polychlorinated biphenyls, chlorinated dioxins and chlorinated furans, bromated flame-retardants (Öman and Junestedt 2008; Qi et al. 2018), perfluorinated alkyl substances (Huset et al. 2011; Fuertes et al. 2017), chlorinated alkylphosphates, pharmaceuticals drugs or personal care products (Eggen et al. 2010; Qi et al. 2018) etc.

Usually, the analysis of these classes of compounds involves chromatographic techniques, the most used being gas chromatography (GC) (Öman and Junestedt 2008; Eggen 
et al. 2010; Ying et al. 2012; Jernberg et al. 2013; Borrás et al. 2016; Kumarathilaka et al. 2016; Khalil et al. 2018) and high performance liquid chromatography (HPLC) (Öman and Junestedt 2008; Eggen et al. 2010; Huset et al. 2011; Fuertes et al. 2017; Pastore et al. 2018) coupled with either selective detectors or mass spectrometry. The main drawback of these techniques is the limited number of compounds that can be analyzed in a single run. As a result, a comprehensive characterization of xenobiotic organic compounds contained in municipal landfill leachate requires multiple analysis rounds which mean time and reagents consumption, and generation of high quantities of waste. (Öman and Junestedt 2008).

Nowadays, comprehensive two-dimensional gas chromatography, coupled with mass spectrometry, becomes an attractive technique for analyzing the complex mixture of organic contaminants in various gaseous, liquid or solid environmental samples, due to its high peak capacity which allows the separation of a huge number of compounds in one run (de Vos et al. 2011; Beldean-Galea et al. 2013; Prebihalo et al. 2015; Beldean-Galea et al. 2017; Muscalu and Górecki 2018, Ieda et al., 2019). Compared to the classical GC technique, which uses a single column for separation, GCxGC uses two columns with different polarities, coupled together through an interface called modulator whose role is to collect the compounds eluted from the first column, their concentration and re-injection in the second column for a new separation. In this way, two separation mechanisms, one based on volatility and the other on polarity, are combined, resulting in improved chromatographic separation due to the increase of peak capacity, lower detection limits (due to the focus of the compounds in modulator) and better identification due to the ability to structure the chromatograms in a chemically ordered manner according to the volatility and polarity of the compounds (Adahchour et al., 2006).

Even with the advantages offered by GCxGC, the chromatographic analysis involves a preliminary step for the extraction of the compounds of interest from the matrix in which they are enclosed so they are amenable to GC analysis. In the case of municipal landfill leachate, 
over the time, different extraction methods, such as solvent extraction (Beldean-Galea et al. 2013; Jernberg et al. 2013; Khalil et al. 2018) or solid phase extraction (Eggen et al. 2010; Huset et al. 2011; Fuertes et al. 2017; Pastore et al. 2018), were applied for the isolation of target compounds. Unfortunately, these methods are expensive, time consuming and produce considerable amount of wastes.

In the last decade, the microextraction techniques in solid-phase (Beldean-Galea et al. 2017) or liquid-phase (Hashemi et al. 2017) became convenient for sample pre-treatment because they only require small volumes of organic solvents or adsorbents to extract a wide variety of analytes from different matrices prior to instrumental analysis.

Of these methods, liquid-phase microextraction (LPME) has become one of the most commonly used extraction procedure for the pre-treatment of environmental, food, and pharmaceutical samples and it was proposed as an alternative solvent-minimizing sample pretreatment technique. The major advance of LPME consists in requiring only a few microliters of solvent to extract a wide variety of analytes from complex matrices. LPME is simple, rapid and has an enrichment factor comparable to or better than traditional LLE techniques (Hashemi et al. 2017).

The purpose of the present study was to develop a method for the analysis, in just a single run, of a wide range of toxicants contained in municipal landfill leachate using dispersive liquid-liquid microextraction (DLLME) and comprehensive two-dimensional gas chromatography coupled with mass spectrometry (GC×GC-qMS).

A strategy based on two-level full factorial experimental design, and on desirability functions, has been used for the optimization of DLLME. The optimal extraction conditions predicted by experimental design and desirability functions were experimentally validated and subsequently applied to the analysis of real-world leachate samples. 


\section{Materials and methods}

\section{Reagents and solutions}

For the optimization of the analytical procedure a standard mixture containing 41 organic compounds at individual concentrations of $1.000 \mu \mathrm{g} \mathrm{mL} \mathrm{m}^{-1}$ was prepared by dissolving the required amount of the pure substances in $50 \mathrm{~mL}$ of n-hexane:acetone $(1: 1 \mathrm{v} / \mathrm{v})$ solvent mixture. Different classes of organic compounds such as hydrocarbons, mono- and polyaromatic hydrocarbons, carbonyl compounds, terpenes, terpenoids, phenols, amines, and phthalates, covering a wide range of physicochemical properties and linked to the municipal landfill leachate were selected (Beldean-Galea et al. 2013). The pure substances, with analytical grade purity, were all purchased from Sigma Aldrich, Supelco and Fluka. The composition of the standard mixture as well as different physicochemical proprieties is given in Table 1.

\section{Table 1}

Analytical grade sodium chloride was obtained from Sigma Aldrich (Saint Quentin Fallavier, France), acetone and n-hexane (99.99\% purity) from Merck (Darmstadt, Germany) and chloroform and acetonitrile (99.99\% purity) from Carlo Erba Reagents (Fontanay-sousbois, France). Helium in purity of $99.9999 \%$ was purchased from Air Liquide, France and ultra-pure water (Milli-Q water) was prepared using a Direct-Q UV 3 system (18.2 M $\Omega . c m)$ from Millipore (Molsheim, France).

\section{Samples}

Municipal landfill leachate samples were collected from a municipal solid waste landfill from Romania and stored in a polyethylene flask at $4^{\circ} \mathrm{C}$. Prior to extraction, the 
leachate samples were filtered through a $0.45 \mu \mathrm{m}$ PTFE membrane (Millipore) in order to remove the suspended particulate matter. The obtained leachate samples were diluted at a ratio of 2:1 $(v / v)$ with Milli-Q water in order to decrease the density of the sample and then subjected to the proposed DLLME procedure. For the collected landfill sample the values measured for the general parameters (chemical oxygen demand (COD), $\mathrm{pH}$, conductivity (EC) and total dissolved solid (TDS)) were $2.212 \mathrm{mg} \mathrm{O}_{2} \mathrm{~L}^{-1}, 7.44,18.640 \mu \mathrm{S} \mathrm{cm}^{-1}$ and $9.330 \mathrm{mg} \mathrm{L}^{-}$ ${ }^{1}$ respectively. The $\mathrm{pH}, \mathrm{TDS}$ and $\mathrm{EC}$ were measured using a Combo $\mathrm{pH} \& \mathrm{EC} / \mathrm{TDS}$ multiparameters by Hanna Instrument, (Cluj-Napoca, Romania), while the COD were determined by titration with $\mathrm{KMnO}_{4}$.

\section{Instrumentation and chromatographic separation}

For all experiments a Thermo Trace $\mathrm{GC} \times \mathrm{GC}$ gas chromatograph equipped with a dual $\mathrm{CO}_{2}$ cryogenic modulator and a quadrupole mass spectrometer (qMS) model Thermo ISQ (Courtaboeuf, France) was used. Helium of high purity at a constant flow rate of $1 \mathrm{~mL} \mathrm{~min}{ }^{-1}$ was used as carrier gas. The mass spectrometer acquisition frequency was $50 \mathrm{~Hz}$, and the SCAN mode was used for data collection, setting a mass range from 50 to $250 \mathrm{amu}$. The ionization was performed by Electronic Ionization using a voltage of $70 \mathrm{eV}$. The ion source and transfer line temperatures were $210^{\circ} \mathrm{C}$ and $280^{\circ} \mathrm{C}$, respectively. The injector temperature was set at $280^{\circ} \mathrm{C}$ and the injection was made in split mode using a split ration of 10 .

The analytes were separated on a set of columns consisting of a Factor Four VF-1 MS column (100\% dimethylpolysiloxane), 30 m length $\times 0.25 \mathrm{~mm}$ ID, $0.25 \mu \mathrm{m}$ film thickness (Agilent) in the first dimension and of a DB-1701 column (14\%-cyanopropyl-phenyl)methylpolysiloxane), $1.5 \mathrm{~m}$ length $\times 0.10 \mathrm{~mm} \mathrm{ID,} 0.10 \mu \mathrm{m}$ film thickness (Agilent) in the second dimension. 
The separation was performed with a gradient temperature of $5.0^{\circ} \mathrm{C} \min ^{-1}$ from 60 to $250^{\circ} \mathrm{C}$. The modulation period was 6 seconds and the initial offset was 0.5 second. A solvent delay of 6.5 min was used.

Data acquisition was performed using the Xcalibur ${ }^{\circledR}$ software and $\mathrm{GC} \times \mathrm{GC}$ data analysis was done using the Chromcard® software.

Identification of the compounds was done by comparison of the obtained mass spectra with those from NIST (2012) and Wiley (10 ${ }^{\text {th }}$ edition) mass spectral libraries.

\section{DLLME procedure}

For the optimization of DLLME a volume of $6 \mathrm{~mL}$ of Milli-Q water was placed in a $10.0 \mathrm{~mL}$ conical glass tube. Then, the Milli-Q water sample was spiked with $50 \mu \mathrm{L}$ of standard mixture at a concentration of $100 \mu \mathrm{g} \mathrm{mL} \mathrm{L}^{-1}$ of each compound and then $\mathrm{NaCl}$ was added into the water sample to increase the ionic strength and implicitly the extraction recovery by salting out effect. For the extraction of target compounds, a mixture of disperser and extraction solvents containing acetonitrile as disperser and chloroform as extraction solvent was rapidly added to the sample followed by manual shaking for $2.0 \mathrm{~min}$. After the formation of the cloudy solution centrifugation was performed for $5 \mathrm{~min}$ at $2264 \mathrm{xg}$ in order to separate the extract from the sample. The amounts of $\mathrm{NaCl}$ and the volumes of acetonitrile and chloroform used for the optimization of DLLME procedure are given in the Statistical approach used for DLLME optimization sub-chapter.

For leachate samples, $4 \mathrm{~mL}$ of filtered leachate were diluted with $2 \mathrm{~mL}$ of Milli-Q water and placed in a $10.0 \mathrm{~mL}$ conical glass tube. An amount of $0.5 \mathrm{~g}$ of $\mathrm{NaCl}$ was added into the sample and subsequently a mixture containing $100 \mu \mathrm{L}$ of acetonitrile and $75 \mu \mathrm{L}$ chloroform was rapidly added to the sample and hand shake gently for $2.0 \mathrm{~min}$. The resulted sample was then centrifuged for $5 \mathrm{~min}$ at $2264 \mathrm{xg}$ in order to separate the extract from the 
sample. After that, the aqueous part was removed and $1.0 \mu \mathrm{L}$ of the extract was manually injected into $\mathrm{GC} \times \mathrm{GC}-\mathrm{qMS}$ for analysis. The volume of extract obtained after each DLLME experiment was measured using microsyringes of 10 and $100 \mu \mathrm{L}$ respectively and subsequently used to calculate the extraction recovery.

The performance of the extraction method was tested by a recovery study performed on a fortified leachate sample.

\section{Enrichment factor and extraction recovery}

In order to assess the efficiency of the analysis method, the enrichment factor $(\mathrm{EF})$ and the extraction recovery (ER) were used.

For DLLME, the EF is defined as the ratio of the concentration of the analyte in the collected organic phase $\left(\mathrm{C}_{\mathrm{col}}\right)$ and the initial concentration of the analyte into the sample $\left(\mathrm{C}_{\mathrm{aq}}\right)$. For our purpose EF was calculated based on the following equation (Wang et al. 2010; Asati et al. 2017; Dil et al. 2017):

$$
\mathrm{EF}=\frac{\mathrm{c}_{\mathrm{col}}}{\mathrm{c}_{\mathrm{aq}}}
$$

The ER is defined as the percentage of the total analyte amount from the sample $\left(\mathrm{n}_{\mathrm{aq}}\right)$ which is extracted into the collected organic phase $\left(\mathrm{n}_{\mathrm{col}}\right)$ :

$$
\mathrm{ER} \%=\frac{\left(\mathrm{n}_{\mathrm{col}}\right)}{\left(\mathrm{n}_{\mathrm{aq}}\right)} \times 100=\frac{\mathrm{c}_{\mathrm{col}} \times \mathrm{V}_{\mathrm{col}}}{\mathrm{c}_{\mathrm{aq}} \times \mathrm{V}_{\mathrm{aq}}} \times 100
$$

where: $\mathrm{V}_{\mathrm{col}}$ and $\mathrm{V}_{\mathrm{aq}}$ represent the volume of the collected organic phase and the volume of the aqueous sample, respectively.

\section{Statistical approach used for DLLME optimization}

Typically, optimizing experimental conditions requires a number of experiments due to the number of variables (or factors) that can affect the experimental results. Traditionally, these conditions are determined using univariate approaches, which consist in changing one 
variable at a time, while keeping the others constant, and observing the subsequent effect (Callao 2014). Unfortunately, the univariate approach is time-consuming and does not enable the assessment of potential interactions between factors.

The multivariate experimental design strategies that simultaneously change variables are used with the goal of reducing the high cost of a univariate strategy and minimizing the number of experiments. The multivariate approach requires few experimental runs and can be used for quantitative and qualitative modeling of relationships between factors and responses (Abdulra'uf and Tan 2013; Dil et al. 2017). The most widely used kind of experimental design, to estimate main effect as well as interactions, is the $2^{\mathrm{n}}$ full factorial design, in which each variable is investigated at two levels (Callao 2014).

In this study, a $2^{3}$ experimental design with a triplicate center point was chosen to study the influence of three variables (volume of disperser and extraction solvents and salt amount) over the extraction efficiency. The considered response was the extraction recovery of each compound. To determine the effects of factors and interactions on DLLME and therefore the conditions that give the highest extraction recovery, the JMP11 statistical software package (SAS Institute, Cary, NC, USA) was used.

The minimum $(-1)$, the medium $(0)$ and the maximum $(+1)$ values for each variable have been established before applying the experimental design and the considered values were as follow: extraction solvent volume $\left(\mathrm{X}_{1}\right)(-1=40,0=70$ and $+1=100 \mu \mathrm{L})$; dispersion solvent volume $\left.\mathrm{X}_{2}\right)(-1=100,0=550$ and $+1=1000 \mu \mathrm{L})$; salt amount $\left(\mathrm{X}_{3}\right)(-1=0,0=250$ and $+1=500 \mathrm{mg}$ ) respectively.

In order to perform the simultaneous optimization of the factors to reach the maximal extraction recovery yields, a desirability approach was used (Ferey et al. 2013; Alinat et al. 2015; Deblonde et al. 2016). Individual desirability used was very simple as it corresponded to the higher the extraction recovery, the better the desirability, i.e. desirability value was 
respectively 0 for an extraction recovery of zero, and 1 for the maximum extraction recovery with a linear variation in between. All the individual desirabilities had the same weight in the overall desirability function. The combination of the $2^{3}$ design and the desirability approach aimed at getting a balance extraction recovery yield for all the compounds.

The selection of the extraction and disperser solvents, which can influence the DLLME recovery, was carried out in preliminary experiments and involved a univariate approach. The results performed in this way showed that acetonitrile as disperser solvent and chloroform as extraction solvent are the best choice for the purposed experiments (supplementary material Figures S1a and S1b).

\section{Results and discussion}

\section{Optimization of DLLME}

The $2^{3}$ full factorial design combined with the desirability approach was applied for the simultaneous optimization of the three factors influencing the DLLME procedure: extraction solvent volume $\left(\mathrm{X}_{1}\right)$ disperser solvent volume $\left(\mathrm{X}_{2}\right)$, and salt amount $\left(\mathrm{X}_{3}\right)$.

The mathematical relationship between the response Y (enrichment recovery) and the three independent variables, $\mathrm{X}_{1}, \mathrm{X}_{2}$ and $\mathrm{X}_{3}$, can be modeled by a linear polynomial equation (Chormey et al. 2018) including 3 linear terms, 3 two-way interaction terms, 1 three-way interaction term, and 1 intercept term, as follows:

$$
Y=\beta_{0}+\beta_{1} X_{1}+\beta_{2} X_{2}+\beta_{3} X_{3}+\beta_{12} X_{1} X_{2}+\beta_{13} X_{1} X_{3}+\beta_{23} X_{2} X_{3}+\beta_{123} X_{1} X_{2} X_{3}
$$

where $\beta_{0}$ is a constant; $\beta_{1}, \beta_{2}$ and $\beta_{3}$ are linear coefficients and $\beta_{12}, \beta_{13}, \beta_{23}$ and $\beta_{123}$ are interaction coefficients. 
For the present study, taking dodecane (C12) as an example, the empirical relationship between the independent variables $\left(X_{1}, X_{2}, X_{3}\right)$ and the response $(Y)$ can be represented by the following equation:

$$
Y=33.95-4.46 X_{1}-5.24 X_{2}-2.67 X_{3}+0.23 X_{1} X_{2}-1.68 X_{1} X_{3}-9.53 X_{2} X_{3}+5.91 X_{1} X_{2} X_{3}
$$

The statistical data processing enabled to establish that the three linear coefficients and were significant with a negative effect. However, this negative effect was counterbalanced by significant interactions between extraction solvent and salt, and between dispersion solvent and salt. The amplitude of these effects can be better observed in the histogram (Table S1) which includes the level of significance for the factors and their interactions. It must be recalled that the magnitude of the influence of the factors is by essence related to the range used for each factor in the experimental design because coded values were used.

Optimal conditions predicted by the model were in coded values: +0.2 for extraction solvent, +1 for salt amount and -1 for disperser volume (Figure S2), which correspond to the following experimental conditions: extraction solvent (chloroform) volume $75 \mu \mathrm{L}$, salt amount (ionic strength) $500 \mathrm{mg}$ and disperser solvent (acetonitrile) volume $100 \mu \mathrm{L}$. These theoretical optimal conditions were then experimentally validated and used for the subsequent experiments. This step is all the more essential as the model chosen in this study is rather simple. Its prediction capabilities could be consequently limited and would be of no interest without a true experimental validation. In the present case, the experimental validation demonstrated unambiguously that the objective of getting experimental conditions with a balanced extraction recovery yield for all the compounds.

\section{Performance of DLLME-GC $\times G C-q M S$ method}


The performance of the developed DLLME-GC $\times$ GC-qMS method was evaluated in terms of in terms of intra- and inter-day precision, linearity, LOD, and LOQ. For this purpose, the following experimental conditions have been used: $6 \mathrm{~mL}$ of Milli-Q water, $75 \mu \mathrm{L}$ of chloroform as extraction solvent, $100 \mu \mathrm{L}$ of acetonitrile as disperser solvent, $500 \mathrm{mg}$ of $\mathrm{NaCl}$ and centrifugation for $5 \mathrm{~min}$ at $2264 \mathrm{xg}$. In order to increase the confidence of the results, the volume of extract obtained after DLLME was measured with a microsyringe of $100 \mu \mathrm{L}$ and subsequently used to estimate the performance of the method. The measured volume was 55 $\mathrm{uL}$ and it was much lower than $75 \mathrm{uL}$ used as extraction solvent. This fact can be a consequence of the dissolution of extraction solvent in the sample due to the fact that the equilibrium between extraction solvent volume, disperser volume and salt amount were not reached. However, the performances of the method were in accordance with the validation requirements and could therefore be used in practice (Table 2).

\section{Table 2}

The precision of the proposed method was assessed by intra-day and inter-day relative standard deviations (RSDs), which were evaluated via analysing of different Milli-Q water samples spiked with $1800 \mathrm{ng}$ of each compound on the same day and on three consecutive days, respectively. The obtained RSD\% values were below $7.7 \%$ for intra-day and below $15 \%$ for inter-day assessment for all tested compounds, being therefore in agreement with the concentrations of pollutants found in landfill leachate and with the requirements of the method validation procedures referring to the compounds at the $\mu \mathrm{g} \mathrm{L}^{-1}$ concentration range (Guidelines for validation of analytical methods for non-agricultural pesticide active ingredients and products).

To study the linearity of the method, $6 \mathrm{~mL}$ of Milli-Q water were spiked with 900 , 1800, 2700, 4500 and 9000 ng of each compound. After DLLME-GC $\times$ GC-qMS analysis of 
each sample a calibration curve was constructed using peak area versus concentration of the analyte. The results showed a good linearity of the method, the correlation coefficients $\left(\mathrm{R}^{2}\right)$ being greater than 0.99 for almost all compounds except for 2,3-dimethylphenol, $p$ isopropylphenol, dibutyl phthalate and 4-tert-butylbenzamide for which the $\mathrm{R}^{2}$ values were lower.

The LOD and LOQ of the tested compounds were determined by statistical approach using the standard deviation SD of the regression line (s), the slope (S) of each calibration curve and the enrichment factors. For the tested compounds the LODs ranged from 1.01 to $69.30 \mu \mathrm{g} \mathrm{L}^{-1}$ and LOQs from 1.87 to $138.6 \mu \mathrm{g} \mathrm{L}^{-1}$.

Regarding the extraction efficiency, the results demonstrated that the developed extraction protocol shows good extraction recovery $(\mathrm{ER}=63.8-127 \%)$ and enrichment factor $(\mathrm{EF}=69.6-138.5)$, being comparable with those of the classical solvent extraction method (Beldean-Galea et al. 2013). Moreover, if the predicted and experimentally obtained ER values are compared it can be observed that a better ER was obtained experimentally, meaning that, while the models are not perfect, the method has good real-life performance.

\section{Analysis of real-world leachate samples}

In order to test the applicability of the developed DLLME method to real-world samples, recovery studies of selected compounds from spiked leachate samples were carried out.

For this purpose, $4 \mathrm{~mL}$ of leachate sample were filtered through PTFE membrane of $0.45 \mu \mathrm{m}$ in order to remove the suspended particulate matter and then spiked with $6750 \mathrm{ng}$ of each compound. The resulting sample was then diluted in two milliliters of Milli-Q water and subjected to DLLME and GC $\times \mathrm{GC}-\mathrm{qMS}$ analysis according to the previously described protocol. 
The GC $\times$ GC TIC chromatogram provided sufficient resolution for separating all tested compounds based on their volatility and polarity (Figure 1A and 1B). Moreover, it can be observed that the complex composition of the leachate sample was vastly simplified by the structured $\mathrm{GC} \times \mathrm{GC}$ chromatogram, which produces distinct spaces for different chemical families.

Figure 1.

Regarding the extraction recovery of selected compounds from the spiked leachate sample, the obtained results suggest that the developed DLLME-GCxGC-qMS method provided a recovery of over $80 \%$ for virtually all tested compounds, with the exception of hydrocarbons, monoaromatic compounds and heavy PAHs, for which the ER was lower (Table 3). This could be explained by the interaction of these highly lipophilic compounds with dissolved organic matter from the leachate samples (Öman and Junestedt 2008), which leads to lower recoveries compared to the Milli-Q water samples.

Table 3.

The concentrations of the identified compound classes range from: not detected to 173 $\mu \mathrm{g} \mathrm{L} \mathrm{L}^{-1}$ for alkyl-benzenes, not detected to $1074 \mu \mathrm{g} \mathrm{L}^{-1}$ for polyaromatic hydrocarbons, 65 to $820 \mu \mathrm{g} \mathrm{L}^{-1}$ for carbonyl compounds, 112 to $131 \mu \mathrm{g} \mathrm{L}{ }^{-1}$ for terpenes and terpenoids, 268 to 316 $\mu \mathrm{g} \mathrm{L} \mathrm{L}^{-1}$ for phenols, not detected to $358 \mu \mathrm{g} \mathrm{L}^{-1}$ for phthalates, $79 \mu \mathrm{g} \mathrm{\textrm {L } ^ { - 1 }}$ for diphenylamines, and $232 \mu \mathrm{g} \mathrm{L}^{-1}$ for benzothiazole. Decane was the only identified saturated hydrocarbon, at a concentration of $92 \mu \mathrm{g} \mathrm{L}{ }^{-1}$. 
Comparison of measured concentrations to the predicted no-effect concentration (PNEC) (Thermo Fischer chemical product data) shows that, in most cases, real-world leachate samples contained concentrations exceeding the established PNEC for fresh water (Table 3), meaning that the analyzed leachate is highly toxic and poses an environmental risk if it spills into a natural water system.

Tentative identification of different classes of organic compounds in municipal landfill leachate.

The GCxGC technique allows the separation of complex mixtures and, if coupled with mass spectrometry, offers the possibility of a better identification of the compounds that are not included in the standard mixture, due to its ability to structure the compounds in a chemically ordered manner according to their volatility and polarity

In the case of the analyzed leachate sample, the identification of the compounds was performed by comparing the obtained mass spectra with those of the NIST (standard) and Wiley mass spectral library (Table S2). Only compounds for which the probabilities exceeded $60 \%$ were considered. In the absence of a reference standard, for the considered compounds, their position on $2 \mathrm{D}$ chromatogram (retention time in the first and second dimensions) was compared with the position of compounds from the same family used as standard mixture in order to increase confidence in identification. The assigned numbers in the chromatograms (Fig. 1A and Fig 1B), compound names, molecular structures, molecular ions, the retention times in $1^{\text {st }}$ and $2^{\text {nd }}$ dimension and the probabilities of the similarity between the NIST (standard) or Wiley mass spectra library and the obtained mass spectra in the analyzed sample are given in Table 4 .

Table 4. 
31 compounds from different chemical families such as indoles, pyrroles, glycols, organophosphate flame retardants, pesticides, aromatic amines and amides, pharmaceuticals, and bisphenol A were tentatively identified. Many other compounds were separated but could not be identified due to technical limitations.

Multiple tentatively identified compounds, including organophosphate flame retardants, bisphenol A, aniline, $p$-Aminotoluene, N-Ethyl-o-toluensulfonamide, 4,4'Methylenebisbenzenamine, N,N-Diethyl-3-methylbenzamide, lidocaine, are considered substances of very high concern or emerging pollutants that require monitoring. The developed DLLME-GCxGC-MS method was demonstrated to be an appropriate technical solution for monitoring these pollutants in landfill leachate.

\section{Conclusions}

The developed DLLME-GC $\times$ GC-qMS method for the analysis of multiclass analytes in municipal landfill leachate is simple, fast and inexpensive. It requires considerably reduced sample and extraction solvent amounts and the performance of the analysis is comparable to that of classical solvent extraction.

The method proved its applicability for the analysis of real-world leachate samples and it was able to identify over 70 xenobiotic organic compounds per sample within a total analysis time of 40 minutes, with a sample preparation time of 10 minutes and using only 75 $\mu \mathrm{L}$ of extraction solvent.

Compounds with high toxicity such as polyaromatic hydrocarbons, organophosphate flame retardants, phthalates, phenols, bisphenol A, aniline, $p$-Aminotoluene, N-Ethyl-otoluensulfonamide, 4,4'-Methylenebisbenzenamine, N,N-Diethyl-3-methylbenzamide, diphenylamine and various terpenes were tentatively identified in a single run. The measured 
concentrations of these compounds exceeded the established PNEC for fresh water, posing a risk of toxicity for aquatic ecosystems.

\section{Acknowledgements}

This work was performed in the frame of the Romania - France Bilateral Cooperation, Program Brâncuși, Project no. 774/2014 funded by UEFISCDI - Romania, Project no 32654NJ funded by Campus-France and Program Chaire Joliot founded by ESPCI-Paris.

\section{References}

Abdulra'uf LB, Tan GH (2013) Multivariate study of parameters in the determination of pesticide residues in apple by headspace solid phase microextraction coupled to gas chromatography-mass spectrometry using experimental factorial design. Food Chem 141:4344-4348. https://doi.org/10.1016/j.foodchem.2013.07.022

Adahchour M, Beens J, Vreuls RJJ, Brinkman UATh (2006) Recent developments in comprehensive two-dimensional gas chromatography $(\mathrm{GC} \times \mathrm{GC})$ : I. Introduction and instrumental set-up. TrAC-Trends Anal Chem 25(5):438-454. https://doi.org/10.1016/j.trac.2006.03.002

Alinat E, Delaunay N, Archer X, Vial J, Gareil P (2015) Multivariate optimization of the denitration reaction of nitrocelluloses for safer determination of their nitrogen content. Forensic Sci Int 250:68-76. https://doi.org/10.1016/j.forsciint.2015.03.001

Asati A, Satyanarayana GNV, Patel DK (2017) Comparison of two microextraction methods based on solidification of floating organic droplet for the determination of multiclass analytes in river water samples by liquid chromatography tandem mass spectrometry using Central Composite Design. J Chromatogr A 1513:157-171. https://doi.org/10.1016/j.chroma.2017.07.048 
Baderna D, Maggioni S, Boriani E, Gemmab S, Molteni M, Lombardo A, Colombo A, Bordonali S, Rotella G, Lodi M, Benfenati E (2011) A combined approach to investigate the toxicity of an industrial landfill's leachate: Chemical analyses, risk assessment and in vitro assays. Environ Res 111:603-613. https://doi.org/10.1016/j.envres.2011.01.015

Beldean-Galea MS, Thiebaut D, Vial J, Coman V (2017) Identification of complex volatile organic compounds in municipal landfill leachate by head space solid phase microextraction and GCxGC-qMS analysis. Stud U Babes-Bol Che LXII(3):35-44. DOI:10.24193/subbchem.2017.3.03

Beldean-Galea MS, Vial J, Thiebaut D (2013) Development of a screening method for the determination of xenobiotic organic pollutants in municipal landfill leachate using solvent extraction and comprehensive GCxGC-qMS analysis. Cent Eur J Chem 11:1563-1574. https://doi.org/10.2478/s11532-013-0298-0

Borrás E, Tortajada-Genaro LA, Muñoz A (2016) Determination of reduced sulphur compounds in air samples for the monitoring of malodour caused by landfills. Talanta 148:472-477. https://doi.org/10.1016/j.talanta.2015.11.021

Budi S, Suliasih BA, Othman MS, Heng LY, Surif S (2016) Toxicity identification evaluation of landfill leachate using fish, prawn and seed plant. Waste Manag 55:231-237. https://doi.org/10.1016/j.wasman.2015.09.022

Callao MP (2014) Multivariate experimental design in environmental analysis. TrAC-Trends Anal Chem 62:86-92. https://doi.org/10.1016/j.trac.2014.07.009

Carl Roth chemicals, https://www.carlroth.com/en/en/Chemicals (accessed on July 07, 2019)

Chormey DS, Bodur S, Baskın D, Firat M, Bakırdere S (2018) Accurate and sensitive determination of selected hormones, endocrine disruptors, and pesticides by gas chromatography-mass spectrometry after the multivariate optimization of switchable 
solvent liquid-phase microextraction. J Sep Sci 41:2895-2902. https://doi.org/10.1002/jssc.201800223

de Vos J, Dixon R, Vermeulen G, Gorst-Allman P, Cochran J, Rohwer E, Focant JF (2011) Comprehensive two-dimensional gas chromatography time of flight mass spectrometry (GCxGC-TOFMS) for environmental forensic investigations in developing countries. Chemosphere 82:1230-1239. https://doi.org/10.1016/j.chemosphere.2010.12.039

Deblonde GJP, Chagnes A, Cote G, Vial J, Rivals I, Delaunay N (2016) Development of a capillary electrophoresis method for the analysis in alkaline media as polyoxoanions of two strategic metals: Niobium and tantalum. J Chromatogr A 1437:210-218. https://doi.org/10.1016/j.chroma.2016.01.075

Dil EA, Ghaedi M, Asfaram A, Zare F, Mehrabi F, Sadeghfar F (2017) Comparison between dispersive solid-phase and dispersive liquid-liquid microextraction combined with spectrophotometric determination of malachite green in water samples based on ultrasound-assisted and preconcentration under multi-variable experimental design $\begin{array}{llll}\text { optimization. } & \text { Ultrason } & \text { Sonochem }\end{array}$ https://doi.org/10.1016/j.ultsonch.2017.05.011

Ding Y, Cai C, Hu B, Xu Y, Zheng X, Chen Y, Wu W (2012) Characterization and control of odorous gases at a landfill site: A case study in Hangzhou, China. Waste Manag 32:317-26. https://doi.org/10.1016/j.wasman.2011.07.016

Eggen T, Moeder M, Arukwe A (2010) Municipal landfill leachates: A significant source for new and emerging pollutants. Sci Total Environ 408:5147-5157. https://doi.org/10.1016/j.scitotenv.2010.07.049

Ferey L, Delaunay N, Rutledge DN, Huertas A, Raoul Y, Gareil P, Vial J (2013) Use of response surface methodology to optimize the simultaneous separation of eight polycyclic aromatic hydrocarbons by capillary zone electrophoresis with laser-induced 
fluorescence detection. J Chromatogr A 1302:181-190. https://doi.org/10.1016/j.chroma.2013.06.027

Fuertes I, Gomez-Lavín S, Elizalde MP, Urtiaga A (2017) Perfluorinated alkyl substances (PFASs) in northern Spain municipal solid waste landfill leachates. Chemosphere 168:399-407. https://doi.org/10.1016/j.chemosphere.2016.10.072

Ghosh P, Thakur IS, Kaushik A (2017) Bioassays for toxicological risk assessment of landfill leachate: A review. Ecotoxicol Environ Saf 141:259-270. https://doi.org/10.1016/j.ecoenv.2017.03.023

Guidelines for validation of analytical methods for non-agricultural pesticide active ingredients and products. Available at: http://www.hse.gov.uk/biocides/copr/pdfs/validation.pdf (accessed: January 20, 2019)

Hashemi B, Zohrabi P, Kim KH, Shamsipur M, Deep A, Hong J (2017) Recent advances in liquid-phase microextraction techniques for the analysis of environmental pollutants. TrAC-Trends Anal Chem 97:83-95. https://doi.org/10.1016/j.trac.2017.08.014

Huang JH, Ilgen G, Vogel D, Michalzik B, Hantsch S, Tennhardt L, Bilitewski B (2009) Emissions of inorganic and organic arsenic compounds via the leachate pathway from pretreated municipal waste materials: a landfill reactor study. Environ Sci Technol 43:7092-7097. https://doi.org/10.1021/es901605q

Huset CA, Barlaz MA, Barofsky DF, Field JA (2011) Quantitative determination of fluorochemicals in municipal landfill leachates. Chemosphere 82:1380-1386. https://doi.org/10.1016/j.chemosphere.2010.11.072

Ieda T, Hashimoto S, Isobe T, Kunisue T, Tanabe S (2019) Evaluation of a data-processing method for target and non-target screening using comprehensive two-dimensional gas chromatography coupled with high-resolution time-of-flight mass spectrometry for 
environmental

samples.

Talanta

194:461-468.

https://doi.org/10.1016/j.talanta.2018.10.050

Jernberg J, Pellinen J, Rantalainen AL (2013) Qualitative non-target analysis of landfill leachate using gas chromatography time-of-flight mass spectrometry. Talanta 103:384391. https://doi.org/10.1016/j.talanta.2012.10.084

Khalil C, Al Hageh C, Korfali S, Khnayzer RS (2018) Municipal leachates health risks: Chemical and cytotoxicity assessment from regulated and unregulated municipal dumpsites in Lebanon. 208:1-13. https://doi.org/10.1016/j.chemosphere.2018.05.151

Kumarathilaka P, Jayawardhana Y, Basnayake BFA, Mowjood MIM, Nagamori M, Saito T, Kawamoto K, Vithanage M (2016) Characterizing volatile organic compounds in leachate from Gohagoda municipal solid waste dumpsite, Sri Lanka. Groundwater Sustainable Dev 2-3:1-6. https://doi.org/10.1016/j.gsd.2016.04.001

Mavakala BK, Le Faucheur S,. Mulaji CK, Laffite A, Devarajan, N, Biey EM, Giuliani G, Otamonga JP, Kabatusuila P, Mpiana PT, Poté J (2016) Leachates draining from controlled municipal solid waste landfill: Detailed geochemical characterization and toxicity tests. Waste Manag 55:238-248. https://doi.org/10.1016/j.wasman.2016.04.028

Mukherjee S, Mukhopadhyay S, Hashim MA, Gupta BS (2015) Contemporary environmental issues of landfill leachate: assessment and remedies. Crit Rev Environ Sci Technol 45:472-590. https://doi.org/10.1080/10643389.2013.876524

Muscalu AM, Górecki T (2018) Comprehensive two-dimensional gas chromatography in environmental analysis. TrAC-Trends Anal Chem 106:225-245. https://doi.org/10.1016/j.trac.2018.07.001 
Öman CB, Junestedt C (2008) Chemical characterization of landfill leachates - 400 parameters and compounds. Waste Manag 28:1876-1891. https://doi.org/10.1016/j.wasman.2007.06.018

Pastore C, Barca E, Del Moro G, Di Iaconi C, Loos M, Singer HP, Mascolo G (2018) Comparison of different types of landfill leachate treatments by employment of nontarget screening to identify residual refractory organics and principal component $\begin{array}{lllll}\text { analysis. } & \text { Sci } & \text { Total } & \text { Environ }\end{array}$ https://doi.org/10.1016/j.scitotenv.2018.04.135

Pivato A, Gaspari L (2005) Acute toxicity test of leachates from traditional and sustainable landfills using luminescent bacteria. Waste Manag 26:1148-1155. https://doi.org/10.1016/j.wasman.2005.10.008

Prebihalo S, Brockman A, Cochran J, Dorman FL (2015) Determination of emerging contaminants in wastewater utilizing comprehensive two-dimensional gaschromatography coupled with time-of-flight mass spectrometry. J Chromatogr A 1419:109-115. https://doi.org/10.1016/j.chroma.2015.09.080

Qi C, Huang J, Wang B, Deng S, Wang Y, Yu G (2018) Contaminants of emerging concern in landfill leachate in China: A review. Emerg Contam 4(1):1-10. https://doi.org/10.1016/j.emcon.2018.06.001

Renou S, Givaudan JG, Poulain S, Dirassouyan F, Moulin P (2008) Landfill leachate treatment: review and opportunity. J Hazard Mater 150:468-493. https://doi.org/10.1016/j.jhazmat.2007.09.077

Thermo Fischer chemical product data, https://www.fishersci.fr/chemicalProductData_uk/welcome.do (accessed on July 07, 2019) 
Tigini V, Prigione V, Varese GC (2014) Mycological and ecotoxicological characterization of landfill leachate before and after traditional treatments. Sci Total Environ 487:335-341. https://doi.org/10.1016/j.scitotenv.2014.04.026

Wang Y, You J, Ren R, Xiao Y, Gao S, Zhang H, Yu A (2010) Determination of triazines in honey by dispersive liquid-liquid microextraction high-performance liquid $\begin{array}{lllll}\text { chromatography. } & \mathrm{J} & \text { Chromatogr } & \text { A } & \text { 1217:4241-4246 }\end{array}$ https://doi.org/10.1016/j.chroma.2010.03.031 